\title{
PEDAGOGIC AND LEARNING SPACES OF LEADERSHIP DEVELOPMENT: A SECTORAL CASE STUDY
}

\author{
A. M. Jivan \\ Vantage Lab \\ Johannesburg, South Africa \\ e-mail: ajayjivan@gmail.com
}

\section{Paile}

National School of Government
Pretoria, South Africa
e-mail: milly.paile@thensg.gov.za

\section{ABSTRACT}

This article advances the critical reviews of the leadership development terrain and argues for the necessity to consider and explore the pedagogic spaces of leadership development and its constitutive dynamics. It first synthesises the theoretical debates on pedagogic space by identifying five relevant themes and how pedagogic and learning spaces are differentiated. It locates itself within these debates, focusing on assemblage, embodiment and enactment. It then draws on a case study of the South African retail banking sector to suggest a sectoral analysis. The value and contribution of this case is the attention to different levels of analysis and the theme of journeys. It allows for the consideration of the evolving roles and partnerships of the business schools; and deliberation on expanding and opening up pedagogic and learning spaces. These provoke questions on the roles, nature and values of pedagogy and higher education.

Keywords: pedagogic space, learning space, leadership development, assemblage, levels of analysis, journey, banking sector.

\section{INTRODUCTION}

The leadership development terrain comprises a range of learning and developmental modalities and forms of delivery. Despite this range there are many critical reviews of this terrain, which call for a shift from the predominant focus on individual leaders, their competencies and aligned programmes (see for example, Collinson 2014; Mabey and Morrell 2011). This follows from the challenges to both the individualistic and trait-based conceptions of leadership and the identified limits of the related competency and programme-based articulation of leadership development.

These challenges result from, firstly, the debates on contextualisation and contingency. Secondly, they also arise from surfacing the definitional and conceptual issues regarding 
management, leadership and the development thereof as well as competency, competence and performance, for example. Thirdly, in certain cases, they develop from the interrogation of the underlying positivist and behaviourist assumptions and attendant methodological individualism; and the arguments for the socially constructed or constituted nature of leadership, its development and context from a social constructionist perspective.

Developing these critical reviews, we argue for the necessity to consider and explore the pedagogic spaces of leadership development and its constitutive dynamics. We first discuss the varied definitions, elaborations and meanings given to pedagogic space in the literature; and point out the need to differentiate between pedagogic and learning spaces. We then identify five relevant themes to help locate the analytical and theoretical debates and our position in relation to these. There are similar philosophical, methodological and critical positions within these debates as those in the literature on leadership, its development and context. Following this, we discuss the case study of the South African retail banking sector.

\section{DEFINING AND FRAMING THE PEDAGOGIC SPACE}

At first sight, pedagogic space appears rather obvious and concrete. It has the quality of "being there". However, this everyday familiarity belies the social and conceptual complexities and contestations involved. For the purpose of this article, we identify two broad categories of definitions and uses of pedagogic space. In the first case, it seems that pedagogic space is taken as self-evident, whether it is a tacit pointer to, or explicit equivalence with, a concrete referent such as the classroom, a lecture hall or another formal learning site. For example, on the topic of digitalisation and blended learning, Jewitt, Moss and Cardini $(2007,303,315)$ discuss the tension between print and digital instructional modalities in a classroom as well as that between the "traditional pedagogic space" and the space of "digital-multimedia design principles". Willis $(2014,3)$ discusses the reshaping of the physical space of the classroom "to enter into a new pedagogic space". This "transitioning into newly designed learning spaces" allows the introduction of digital, mobile, independent and participatory learning. Here, we are confronted with the question of how we conceptually distinguish between pedagogic and learning space (Mulcahy, Cleveland and Aberton 2015).

In the second case, these supposedly concrete referents are explored, questioned and/or reframed. This may include exploring or questioning language, representation, meaning, knowledge and the nature of "things", artefacts, space and social phenomena. Parker $(2006,2)$, for example, explores the post-Apartheid reforms of mathematics education in South African schools and the resulting shifts in, and negotiation of, "pedagogic identities" and the "control of the pedagogic space" $(2006,7)$. From the standpoint of higher education in Apartheid and 
post-Apartheid South Africa, Le Grange (2000) draws on Pendlebury's (1998, 345) argument that the pedagogic space is "defined by, among other things, the curriculum, modes of transmission, rules of access and combination, [and] the sites in which teaching and learning occur and by who counts as a teacher and learner". That is, "who may learn (or teach), how and what they learn (or teach), when and for how long and where" (italics in original, 1998, 155). This definition helps locate the specific spaces or "sites of teaching and learning" within the pedagogic space.

As can be gleaned from the above sample of the literature, there are significant differences in assumptions regarding space, time and the social world, along with curriculum, instruction and the nature and values of pedagogy. To help locate the analytical and theoretical debates and our position in relation to these, we identify the below themes.

\section{KEY THEMES ON PEDAGOGIC AND LEARNING SPACE}

We identify five relevant themes that reflect the different possible analytical and theoretical entry points to examining the pedagogic spaces of leadership development. We locate our position in relation to these themes and focus in particular on assemblages, embodiment and enactment. For the purposes of this article we do not unpack the analytical and theoretical differences and nuances within each theme.

\section{Physical and architected constructions}

Taken as a physical extent, pedagogic space refers to an actual classroom or similar site; or an ideal type of an enclosed or bounded formal learning space (Forbes and Weiner 2012; Gislason 2010). The architected construction and bounded frame serve as the standard or universal blueprint of this apparent self-contained space, which is viewed as a "container" (Taylor 2013, 688 ) of learning and learning outcomes. While we may see the interchangeable use of pedagogic space and learning space, certain authors may address how the supposed selfcontained form and space has evolved over time.

\section{Modalities-based interactions and processes}

Here the pedagogic space is framed by, and emerges from, the instructional and learning modalities, together with the possible and permitted transactions, interactions and learning and development processes these entail (Gislason 2010; Jewitt et al. 2007). The modalities serve as a structure and enabler of interactions that can be intra-individual, inter-individual, triadic and group-based; as well as physical, mental and virtual. In this interchangeable use of pedagogic space and learning space, there may be debates on the locus of these spaces. For example, 
consider the critical debates that question the absolute distinctions drawn between pedagogy, andragogy and heutagogy (Merriam 2001a).

\section{Cultural and discursive constructions}

In contrast to the above assumptions of the pedagogic space as a given or static entity (whether a classroom or instructional modality), here it is argued that it is a meaningful socio-cultural or socially constructed space (Kostogriz 2006; Stevenson 2008). It requires the exploration and critique of symbolic, cultural and discursive practices within and outside of the classroom. A step further, these very sites themselves are interrogated as socio-cultural or discursive constructions; as sites of social, cultural or discursive contestations and marginalisation (Kostogriz and Peeler 2007). This includes contestations regarding identities, roles, authorisation, hierarchies, knowledge and representation (Bozalek and Zembylas 2017). For example, the ongoing interrogation of the South African higher education curricula and sites of learning illustrates how the assumption of a fixed, universal or a priori template of pedagogic space is being challenged. These contestations open up the question of the textuality of the constructed and experienced pedagogic space. This means that the architecture is approached as a socio-cultural or discursive construction within everyday exchanges. However, this understanding still does not address the materiality of the architecture and, by implication, how we account for the materiality of pedagogic spaces.

\section{Embodied spaces of socio-material realities}

An account of materiality could return attention to the physical and architectural modalities of pedagogic institutions, and how these bound and shape the lived experience and discursive constructions. Consequently, as material and designed structures, pedagogic institutions have agency. However, this view of materiality retains an implicit dichotomy of the physical/natural/material and the social/constructed-technological/discursive-constructions (Hopwood et al. 2016). This dichotomy is questioned and problematised in the poststructuralist, post-modernist and certain social constructionist conceptualisations of sociomaterial and embodied realities, which draws on a particular understanding of power, discourse, practices, and relations (Jivan 2017; Taylor 2013).

It means there is no a priori natural reality, materiality, body or space that one can access. These are "always already" socially mediated and constituted by both discursive and material practices. These same practices are implicated in the process and dynamics of embodiment and enactment as and by individual subjects. Thus, pedagogic space can be described as embodied spaces of socio-material realities. This means that "context is an effect of, rather than pre- 
existing, the practices that give rise to it" (italics added, Edwards and Miller 2007, 269).

\section{Networks and assemblages}

A focus on the physical and architectural modalities of pedagogic institutions can be broadened to its networks of instructional, communicative, technical and other modalities. Further, it can be broadened to the various institutions and networks, and their modalities that the pedagogic institutions themselves are embedded within. This includes statutory institutions and networks of allied institutions where the policies of education, skills development, labour and industrialisation, for example, are initiated, developed and executed (Pendlebury 1998). These very policies define and frame the nature and forms of curriculum, education and skills development.

The concept of assemblages is applicable to these networks of institutions, the layers of networks of modalities, the policy space and the embedded pedagogic space. We read the concept as further developing our spatial and temporal understanding of socio-material and embodied realities (Decuypere and Simons 2016; Moisio and Kangas 2016). According to Koyama and Varenne $(2012,157)$, for example, assemblage "focuses analytic attention on how disparate material and discursive practices come together to form dynamic associations". For Baker and McGuirk (2017, 428), assemblage comprises "arrangements of humans, materials, technologies, organizations, techniques, procedures, norms, and events, all of which have the capacity for agency within and beyond the assemblage". They argue that "assemblages consist of and create spatialities". It involves "ongoing processes of deterritorialization and reterritorialization".

This suggests the need to explore and critically examine the particular arrangement of socio-material and embodied realities within specific locales. It requires us to pay attention to how particular networks, configurations of institutions and practices, and "geographies" come together, are arranged, and are embodied and enacted (Decuypere and Simons 2016; Richer 2015). That is, the evolving socio-topologies, socio-topographies and textuality. We locate ourselves within this framing of pedagogic space as assemblage. We explore this through a sectoral analysis and the theme of organisational and personal journeys. These journeys also illustrate how higher education, through the business schools, is implicated in different roles and in the shaping of pedagogic and learning spaces.

\section{A CASE STUDY OF SECTORAL LEADERSHIP DEVELOPMENT}

The sectoral analysis draws on the qualitative case study by the first author on leadership development in the South African retail banking sector. The case study is based on Merriam 
(2001b) and Yin's (2003) description of it as a research design. It comprises thirty-one semistructured interviews conducted by the author at multiple sites. The first site was the retail banks and included the heads of the Leadership Development Centres (LDCs) of the four large retail banks and one small retail bank. The second site was the Banking Sector Education and Training Authority (BANKSETA). It comprised interviews with the Chief Executive Officer (CEO) and the past and present skills development managers responsible for the BANKSETA International Executive Development Programme (IEDP); and sourcing of open access documents on the BANKSETA and related national strategy, policy and legislation. The third site was a local university business school in the province of Gauteng that hosted the BANKSETA IEDP, which included the programme managers, faculty and coaches of the IEDP, and a sample from two cohorts of the IEDP delegates who work in the five banks.

The case study uses the "constant comparative method" (Merriam 2001b, 159), a form of qualitative thematic analysis, to surface themes, to conduct within and between case analysis, and develop thick descriptions. It unearths how leadership development has evolved within the LDCs of the banks and the BANKSETA International Executive Development Programme (IEDP). This is through the themes of organisational and personal journeys. Although some of the research participants may have since changed portfolios, this article refers to their roles at the time of interviews during 2014-2016.

We begin with the discussion of the BANKSETA within the evolving skills development and education architecture. This provides the setting for exploring the BANKSETA and LDCs' institutional journeys; and, thereafter, the individual journeys and lived experience. These then lead to a closing discussion on competencies, creating spaces and the roles of the business school.

\section{BANKSETA and the skills development and education architecture}

The BANKSETA and the other Sector Education and Training Authorities (SETAs) were enacted through the Skills Development Act (1998 and amended in 2008). The Act forms part of the evolving corpus of strategy, policy and legislative interventions within the post-Apartheid state. These interventions include the White Paper on Higher Education Transformation (Department of Education (DoE) 1997) and the National Qualifications Framework Act (South African Qualifications Authority (SAQA) 2008), and iterations of the National Skills Development Strategy and National Human Resource Development Strategy (Department of Higher Education and Training (DHET) 2011). Together they articulate the intended state apparatus to address the Apartheid legacy of "inequitable distribution of access and opportunity" (DoE 1997, 4) and "promote a skills development system and architecture that 
effectively responds to the needs of the labour market and social equity" (DHET 2011, 6).

The Skills Development Act was thus proclaimed with the following diverse purposes. To address "the quality of life of workers and their prospects of work" as well as "productivity in the workplace and the competitiveness of employers"; together with "investment in education and training" and the "use [of] the workplace as an active learning environment" (Department of Labour (DoL) 1998, 4). It specifically aims "to improve the employment prospects of persons previously disadvantaged by unfair discrimination and to redress those disadvantages through training and education" $(1998,5)$. The Act, therefore, makes provision for SETAs to coordinate and facilitate the "transformation agenda [and] targets" (BANKSETA CEO) and the investment in human resource development, along the National Qualifications Framework and Occupational Qualifications Sub-Framework levels, in the various sectors of the economy through a levy-grant scheme. Accordingly, the BANKSETA defines its mission and vision in relation to these diverse purposes and the funding afforded it (BANKSETA 2018):

"To support transformation and people development and through partnerships, to enable stakeholders to advance the national and global position of the broader banking and microfinance sector." (italics added)

"To be recognised as a centre of excellence and innovation for skills development in the [...] sector." (italics added)

This is reflected in the BANKSETA's leadership and executive development programme that is hosted at a local business school, which aims to be transformational, capacitating and novel:

\begin{abstract}
"One of the primary functions is to assist in the social transformation of the banking sector and the International Executive Development Programme (IEDP) [is] aimed at providing opportunities for historically disadvantaged [individuals] to access development opportunities at the highest levels both locally and internationally.” (previous BANKSETA CEO, Groenewald 2007)

"[...] increasing the pool of South African bankers with international experience" (BANKSETA 2007)

"[The IEDP] is unique in that it is a six-week international experience within a four-month highimpact programme. Programmes of this nature are generally of [..] shorter duration. It is also unique in that it is a cross-organisation programme." (BANKSETA 2006)
\end{abstract}

It is also reflected in its investment in developing the capabilities of the basic and higher education value chain and the "throughput" (BANKSETA CEO) of the institutions therein. For example, the CEO cites the "Thuthuka programme" to develop black Chartered Accountants in partnership with the South African Institute of Chartered Accountants and various universities. Thus, the BANKSETA attempts to draw linkages between basic education, higher education 
and skills development.

The above strategy, policy and legislative interventions also signal the need to grapple with global and local realities and challenges; including those within institutions. For example, the "complex array of different directorates" within the national departments demonstrate that these are not "homogenous entit[ies]" (DHET 2013, 6). Similarly, the metaphor of the BANKSETA and other SETAs as delimiting the formal "architecture" (DHET 2011, 6) and ecosystem for skills development does not imply an enclosed, internally coherent structure; nor a self-sustained one. This is evident in the elaboration by the BANKSETA CEO when he describes the SETA framework as being both "unique" and open to appropriating influences from other contexts such as "what the Canadians had". Simultaneously, he argues for the need to deliberate on the lifespan of SETAs and to evolve skills development and education in alignment with the broader socio-economic ideals of the National Development Plan (NDP). "SETAs, we're only referring to, answering the transformation targets only."

The BANKSETA CEO points to the hybrid influences in the macro-level policy and institutional spaces. Various authors, from the policy and/or academic contexts, similarly argue that the policy space comprises the confluence of local, continental, global and multilateral actors and networks as well as consequent trade-offs and contestations (Allais 2012; Kanwar, Balasubramanian and Umar 2013; McGrath and Badroodien 2006; Tuschling and Engemann 2006). These hybrid influences, trade-offs and contestations frame skills development and education agendas within competing discourses. As can be seen in the above-quoted diverse purposes of the Skills Development Act, these are discourses of employability, economic growth, sustainable development, human development, lifelong learning and an active and empowered citizenry.

As with management education and leadership development at local and global business schools and firms in general (Furlonger 2015; Khurana 2010), these discourses and textualities are crystallised in the IEDP and LDCs as the balance between academic rigour on the one hand, and social or business relevance on the other. This framing of a balance and the dynamics thereof can be seen in the discussion in the next section; for example, on the content themes within programmes and the nature of learning spaces, developmental processes therein, and the partnerships these entail. The dynamics illustrates how the BANKSETA and banks' LDCs navigate, incorporate, expand and challenge the existing education and training ecosystem of infrastructure, facilities, modalities and providers (such as the business schools); within and beyond the formally defined education and skills development architecture. This provides insight into the complexities, contingencies and dilemmas in their engagement with pedagogic spaces. 


\section{Institutional journeys and the evolving partnerships with business schools}

Given the above hybrid influences, trade-offs and contestations, it is important to gain sight of the institutional realities and dynamics at the meso-level. The BANKSETA management, the local business school hosting the BANKSETA IEDP and the heads of the retail banks' LDCs provide a glimpse into these organisational complexities through their perspectives of their lived experiences. The BANKSETA management and LDC heads navigate and negotiate their respective organisation's mandates, strategy, culture and purposes; the ways their organisations frame leadership, learning and development; and the education and skills development architecture and ecosystem wherein the business schools are intermediaries. They draw on their "sectoral" and "business" or firm-level perspectives and positions to help locate and differentiate themselves from each other and their leadership development.

The focus of this article is on these evolving institutional perspectives and positions as these define and shape how they relate and differentiate themselves from the business schools over time. The business schools themselves have their own higher education institutional perspective and position from which they engage the BANKSETA, banks and others. These different perspectives and positions inform how they differently engage with the pedagogic space and shape, incorporate, and open up learning and developmental spaces to and with the delegates. In turn, it informs how they differently shape the leadership and learning journeys of their respective delegates. However, they also point out that their day-to-day realities and similarities in learning and development brings forth "humility" and the realisation that there are "many levers" and the "interplay" between them. For example, below are descriptions from three heads and the past programme manager at the business school respectively.

"You've got to be humble."

"I am not as arrogant to think that it's only my programme that's making the difference. [..] there's always an interplay between all of us."

"There's so many levers that you have to pull to put all these pieces together. I don't think we've got one answer for it."

"[..] we hope that we set the stage and then other people pick it up along the way."

There is no one ultimate leadership development programme or bounded set of learning and developmental modalities and experiences. In fact, the delegates' journeys straddle the many programmes, modalities and experiences they are exposed to, as will be discussed in the next sections. 


\section{Sectoral leadership transformation and its articulation within the business school}

The BANKSETA IEDP has been evolving since it was first piloted in 2005 at two Canadian business schools. The BANKSETA management sees the IEDP as "complement[ing]" (BANKSETA 2008) the individual bank's existing leadership development initiatives, by facilitating sectoral "transformation" and bringing about "something completely different". This follows from their "sectoral perspective" and mandate, which informs their programme themes and learning spaces for the formal, non-formal and informal learning of their delegates. These spaces include opportunities for delegates to "hear the stories first hand" from key actors and networks in the different contexts, industries and countries. The creation of these learning and developmental spaces evolved as the BANKSETA's networks and partnerships with business schools and international firms developed over time, which reflects the way the BANKSETA framed and gave meaning to its purpose and that of the IEDP. This does not mean there were no challenges, such as the "time [needed to build] relationships" and "manage" "negative perceptions" and "friction that happens" (as the previous skills development manager describes it in relation to the banks and business schools respectively).

As we consider the "sectoral" perspective and position of the BANKSETA, we need to also attend to how the IEDP is given form and articulated at the local business school's executive education where it has been "anchor[ed]" since 2010. The perspectives of the previous and current programme managers at the business school are discussed. The previous programme manager describes how they engaged with the BANKSETA and sector "rationale", while acknowledging the opportunity they were afforded by the substantial BANKSETA funding of the IEDP:

\footnotetext{
"I understand the rationale for the sector [...] I would think that the primary purpose is to develop the participants to be the best leaders that they can be, $[\ldots]$ in that sector in the organisations that are putting them forward and that BANKSETA are selecting against. [...] there are lofty objectives that's framed in the mission and all of that, but it is fundamentally, from my point of view, about developing the leaders so that they really are quite transformed from when they start to when they have finished the programme, but the process continues, so it needs to be self-sustaining."

"Some of [the challenges] are just dealing with BANKSETA in that they have a view as to what they would like. We were lucky, [...] we had very good people to work with, but later on the BANKSETA would say they want to do this, and you might accommodate them, but it doesn't tie in with what you're trying to do."
}

The programme managers add that their "point of view" was informed by their focus on the developmental process and "experiential learning" of the individual delegate as a "leader"; their 
structuring of the programme, including the continental and international "study tours", as a "peer-to-peer education" in alignment with the "relational" "philosophy of learning" of the business school; and the certificate requirements and needed academic rigour of the IEDP. They redesigned the programme they "inherited" accordingly as a "personal development programme" with various "experiential" and "field challenges":

"[...] before the change [to the local business school], the curriculum [was] fairly standard. [...] we inherited some topics which we were happy to inherit."

"I think not only [the "difference" in our "design"], but the people we get to deliver are exceptionally good. So you might inherit economics as a subject, which is quite great to do so they can understand both local and international economies, but the people that we've got to do it would present it in a way that they'll never forget. They're truly engaged [...] and their minds would change."

"[...] engagement and relationships."

"[Leadership and learning are] relationships, and hopefully [the delegates] see it that way too. You're not always just focusing on business aspects. We do have a broader view. [...] There would be some [delegates] and they'd say it's a waste of time. Where's the exam kind of thing."

"[...] so transforming the learning process from a largely classroom-based slash company visit for the international study tours to more of an experiential angle to it, for example, introducing field challenges [including at "informal" markets]"

They attempt to bring about what one of the faculty members presenting on the IEDP describes as the "alignment" of "pedagogy"; that is, the alignment of pedagogic philosophy, design and method. For the programme managers the IEDP is meant to be a "springboard" for the individual delegates' "personal leadership" journey, rather than prescribing a particular leadership theory and related change. It is enabling the delegates' own journey, voice and being; that is, facilitating their development of their "head, heart and hands in leadership" as discussed in the next section.

"I do not think about leadership in terms of the theories of leadership [or "dichotomies sort of model"] anymore, I think about it in terms of how can this person become the best leader that they can possibly become."

"Leadership [is] getting people to work towards goals."

This is similarly the case with the contracted coaches on the IEDP, where the programme managers "don't prescribe a model for coaching". However, they do set the required deliverables and outcomes, such as each delegate's own leadership charter and their action plan to achieve it. These deliverables and outcomes are informed by how they frame the "head, heart and hands in leadership", through combining for instance the "Goleman, Boyatzis and McKee 
[2013] five-step model of ["personal"] change" and the "leadership pipeline approach" of Charan, Drotter and Noel (2011). The banks also use the leadership pipeline model, as discussed below.

\section{Banks' competing demands of, and partnerships with, business schools}

Within the banks the heads of the LDCs wrestle with competing demands. These include the "alignment" of their leadership development to the present "business challenges" as well as the needed "future capability" for the disruptions of the "VUCA" (volatile, uncertain, complex and ambiguous) world, along with their internal organisational dynamics and the evolving capabilities of the LDCs. It is their very location within their respective banks, and their evolving "alignment" and "customisation" of leadership development content, instructional modalities and digitalisation, that the heads of LDCs use to externally differentiate themselves from the business schools.

They frame the general business school approach to leadership development as being rather "academic" and concerned with "SAQA compliance"; placing a high value on "cognitive" and "classroom-based" learning rather than business relevance. Some cite degreed programmes such as the MBA as an exemplar of this; and of the need to "incorporate a personal journey".

"Self-awareness does not happen because of cognitive knowledge [..] universities are doing more of the same. They've added the themes but they're not developing the leaders."

At the same time, though, the managers voice a critical view of their own organisations' narrow attention on immediate business relevance; that is, the focus on "leaders", their business performance and problems, and their related "needs" as defined by the bank's competency and leadership pipeline models. As the conversations with the heads of the LDCs unfold, a call emerges to relook at their "partnership" with the business schools and other "vendors", in order to "create a different model and a different level of thinking". They pose the question of how they can "co-design" and "co-create" leadership development with the business schools and others as partners; and how these partners can "get closer to business".

Likewise, the programme managers at the local business school hosting the BANKSETA IEDP asks the same question of how they can partner with organisations-as-clients and bring the learning and critical reflection process into the workplace. They share their experiences of how client demands for executive education, in-company programmes and its customisation can vary, be conflicted and unrealistic in expectations: 
“[...] it's so easy to say, go to business school for two weeks [and 'you'll develop great leaders']. It's not going to happen."

"[...] your best leadership development is going to take place at work, and therefore you must engineer experiences that will develop people, and these unfortunately are long-term, ['three to five years',] there's a role for us as a university and business school, but the real development must take place within the organisation."

On leadership models, they too speak of the need for a "personal change" journey, as discussed and elaborated on in the next section. Thus, one finds a complex arrangement of differential positioning, given their institutional mandates, purposes and settings; and similarities and nuances in approach to leadership and leadership development between the BANKSETA, banks and business school managers.

The suggestion of "getting closer to business" confronts traditional conceptions of the classroom and learning space. Bringing the "classroom" into the "workplace" and the "workplace" into the "classroom" strains the existing physical, symbolic and discursive boundaries of the client, university and pedagogic spaces. It shows the complexities and dynamics of using the "workplace as an active learning environment" (DoL 1998, 4), as suggested by the Skills Development Act. However, it is limiting as it frames pedagogic space as a physical container and/or instructional modality. We suggest that the above-mentioned dynamics illustrate that pedagogic space is not a singular homogenous space, within which the retail banking sector's leadership development takes place; but rather complex and evolving assemblages that comprise a multiplicity of learning and development spaces, modalities, experiences and purposes as well as client and university interfaces and boundaries that the stakeholders as actors engage with and negotiate over time. Thus, it is important to explore the individual journeys therein.

\section{Individual journeys and lived experience}

The theme of an individual "journey" emerges in the discussions of all the research participants including the delegates of the IEDP. In these discussions they similarly portray leadership development as a continuing learning, developmental and leadership journey for individuals as well as teams; rather than as something simply transferable or acquirable within a class or lecture. Thus, the journey is not confined to or only defined by a single programme. One LDC head clarifies: a programme is "not the end of the conversation". Nor is leadership development taken as a linear or cumulative process across programmes. For example, consider the below descriptions of the IEDP by the former programme manager at the business school: 
"We don't expect the programme to be the end of what they're doing. It will more than likely be the springboard and they carry on. That's why I say one of the things is to inspire them to want to change [their head, heart and hands in leadership]."

"[...] the certificate is really just a point in that journey that continues"

"[...] we hope that we set the stage and then other people pick it up along the way"

Likewise, leadership development is not a linear or cumulative process within a programme. For example, there are twin undertakings by the heads of the LDCs: "[y]ou need to create a context and you need to contain" the individual's journey while including "interruption", "dislodgement" and "uprooting" of the individual delegate through their journey. This means "pushing the limits" and "taking [the delegates] completely out of [their] conformist world" and "comfort zones".

In line with their pedagogy, there are similar descriptions by the IEDP programme managers at the business school and the delegates, such as the need to be "stretched" and to be "forc[ed] to move into areas of discomfort". This unfastening is taken as part of the leadership development journey, as these delegates describe it:

“[...] there's an element initially of being lost in the sea until you find your way [...] you've got to encounter the rough seas first, you've got to feel like you're on a sinking ship before you reach that inflection point and you say okay now."

"Sometimes in the beginning you'll be asking the wrong questions and getting the wrong things and then you keep improving as you go along."

Instead of being an enclosed "container", the business school and IEDP open up spaces for the delegates to explore and deliberate on. This included interactions with different socio-cultural, educational and economic realities during the local, continental and international "study tours" and "field challenges". In this way it afforded the delegates expanded pedagogic and learning spaces. It compelled them to ask questions of their identity, values, purposes and future pathways as well as their knowledge-base in these different spaces. It played a pedagogic and "civic" (Waghid 2008, 20) role, fostering learning as well as "critical reasoning", questions on values and equity, and "deliberation [and contestation] with others".

However, after completing the programme the IEDP delegates voiced the need for a "platform" in their working environment for them to revisit and deliberate on their learning from the IEDP. It speaks to the earlier discussion on bringing the "classroom" into the "workplace" and the "workplace" into the "classroom". The absence of clear avenues and spaces to consolidate and even enact lessons learned from an extensive journey remains the 
shortcoming of many organisational learning and development initiatives, both in the private and public sectors (Daweti and Evans 2017; Jivan 2017). It is a reminder of the tensions and challenges of organisational boundaries, hierarchies and competitive advantages.

\section{Competencies, creating spaces and the roles of business schools}

The lack of avenues and spaces to consolidate and enact lessons learned is also the effect of the discourse and practices of competency-based human resource management and human resource development within the individual banks. As in other private and public sector organisations, competency frameworks are intended as an integrative vocabulary and mechanism between the organisation's business strategy and its operational and talent planning and decisions (Daweti and Evans 2017; Jivan 2017). However, their individual competency frameworks may delimit learning, leadership development and talent management in individualistic, behavioural and decontextualised terms; and within the bounds of the organisational hierarchy. This can be seen in the push for increasingly modular learning content, which allows the banks to selectively purchase and package modules across "vendors" for their "business demands" and "needs" of their "leaders".

Along with the business school participants the heads of the LDCs do identify the above limits stemming from the competency approach and the need to broaden both leader and leadership development; acknowledging there is no one "model" or "standard" of leadership. This includes broader access beyond their organisational hierarchies; peer and collaborative forms of learning as leadership is seen as relational; and associated team and organisational development to "stretch" and "push the limits" of the organisation as a whole, change the culture and open up spaces. The heads though point to the trade-offs within their institutions and need for pragmatism given the contending pressures and timeframes as noted earlier. One could suggest the similar case with the business schools, which are not homogenous institutions. For example, the business school programme managers of the BANKSETA IEDP may negotiate between their "point of view", the many interpretations of the school's mandate, philosophy and pedagogy within, and the prevailing institutional practices, politics and contingencies. Daweti and Evans (2017) point out the similar contention in the public sector.

It is worthy to note that the competency framework of the South African public service is itself adapted from frameworks in Australia, Canada, UK and USA (Department of Public Service and Administration 2003; Jarbandhan 2011). This reinforces the earlier point on hybrid influences and the confluence of local, continental, global and multilateral actors and networks. Therefore, by "intention", expediency and constitutive practices, the macro, meso and microlevel conditions in a particular locale remain open, receptive and bound to "external" 
influences. This raises questions such as the following. What does it mean and take to "live" the shared culture and values of a firm, sector, economy and nation in a transforming South Africa? How are the boundaries between "internal" and "external", at the different levels, evolving? Is there a space for a "more open, critical, cosmopolitan pluriversalism" (Mbembe 2016, 37)?

To address these questions the sector and business school stakeholders need to interrogate the evolving form and nature of their partnerships; and whether these intentionally open up spaces for critical reflection, questions on "social justice", "deliberation with others" (Waghid 2008, 20), contestation and civic agency. That is, whether these enable what Davids and Waghid $(2018,8,10)$ describe as the "pedagogy of discomfort [and] dissonance". In this regard the business schools can help examine and think through hybridity, marginality and textuality. However, it requires them to critically examine the pedagogic, scientific, economic and "civic roles" (Waghid 2008, 20) they and higher education in general are implicated within. This goes beyond the binary of academic rigour versus business relevance.

\section{CONCLUSION}

We argue for the necessity to consider and explore the pedagogic and learning spaces of leadership development and its constitutive dynamics, which include hybridity, marginality and textuality. We draw on a sectoral case study to illustrate these dynamics, the value of attending to different levels of analysis and the institutional and individual journeys therein, and the consequent shaping of pedagogic and learning spaces at these different levels. It provokes us to re-envision, collectively, education, skills development, lifelong learning and the "workplace as an active learning environment" (DoL 1998, 4). It cautions against framing the required change in leadership development as simply a matter of contextualisation or bringing elements of the "classroom" into the "workplace" and the "workplace" into the "classroom". It allows for the consideration of the possible roles of the business schools and universities, and more critical deliberation on expanding and opening up pedagogic and learning spaces. A limitation of the case study is the sole use of one-to-one interviews with the stated sample of stakeholders. Future research could consider network analysis, participant observation and ethnographic studies.

\section{REFERENCES}

Allais, S. 2012. Will skills save us? Rethinking the relationships between vocational education, skills development policies, and social policy in South Africa. International Journal of Educational Development 32(5): 632-642.

Baker, T. and P. McGuirk. 2017. Assemblage thinking as methodology: Commitments and practices for 
critical policy research. Territory, Politics, Governance 5(4): 425-442.

BANKSETA. 2018. About us. https://www.bankseta.org.za/about_us.aspx?section=1\&page=5 (Accessed 7 March 2018).

BANKSETA (2008). BANKSETA enjoys a 'bull run' both locally and internationally. www.bankseta.org.za/.../quarter_4_2008_BANKSETA_Newsletter.pdf (Accessed 8 November 2018).

BANKSETA. 2007. IEDP Programme moves into third year of success. http://www.skillsportal. co.za/content/iedp-programme-moves-third-year-success (Accessed 16 November 2015).

BANKSETA. 2006. BANKSETA CEO flies flag at Canadian conference. http://www.skillsportal.co.za/ content/bankseta-ceo-flys-flag-canadian-conference

Bozalek, V. and M. Zembylas. 2017. Towards a response-able pedagogy across higher education institutions in post-Apartheid South Africa: An ethico-political analysis. Education as Change 21(2): 62-85.

Charan, R., S. Drotter and J. Noel. 2011. The leadership pipeline. How to build the leadership powered company. San Francisco, CA: Jossey Bass.

Collinson, D. 2014. Dichotomies, dialectics and dilemmas: New directions for critical leadership studies? Leadership 10(1): 36-55.

Davids, N. and Y. Waghid. 2018. Resistance and dissonance in higher education: On doing things differently. South African Journal of Higher Education 32(1): 1-12.

Daweti, M. and R. Evans. 2017. Leadership constructions and discourse interfaces in the public service in South Africa. African Journal of Public Affairs 9(8): 151-171. http://hdl.handle.net/10520/EJCab591f970

Decuypere, M. and M. Simons. 2016. Relational thinking in education: Topology, sociomaterial studies, and figures. Pedagogy, Culture \& Society 24(3): 371-386.

Department of Education. 1997. A programme for higher education transformation: Education White Paper 3. Pretoria: Government Printer.

Department of Higher Education and Training. 2011. National skills development strategy III. https://www.nationalskillsauthority.org.za/wp-content/uploads/2015/11/NSDSIII.pdf (Accessed 7 March 2015).

Department of Higher Education and Training. 2013. National skills development strategy III. Progress report 2011-2013. http://www.dhet.gov.za/Booklets/NSDS\%20III\%20Progress\% 20Report\%20\%207\%20October\%202013\%20-\%20V11.pdf (Accessed 7 March 2015).

Department of Labour. 1998. The Skills Development Act, Number 97. Pretoria: Government Printer.

Department of Public Service and Administration. 2003. Senior management service: Public service handbook. http://www.dpsa.gov.za/dpsa2g/documents/sms/publications/smshb2003.pdf (Accessed 9 February 2016).

DHET see Department of Higher Education and Training.

DoE see Department of Education.

DoL see Department of Labour.

Edwards, R. and K. Miller. 2007. Putting the context into learning. Pedagogy, Culture \& Society 15(3): 263-274.

Forbes, J. and G. Weiner. 2012. Spatial paradox: Educational and social in/exclusion at St Giles. Pedagogy, Culture \& Society 20(2): 273-293.

Furlonger, D. 2015. Treading carefully. African management education. Financial Mail September 2430: $22-32$.

Gislason, N. 2010. Architectural design and the learning environment: A framework for school design research. Learning Environments Research 13(2): 127-145. 
Goleman, D., R. E. Boyatzis and A. McKee. 2013. Primal leadership: Unleashing the power of emotional intelligence. Boston: Harvard Business Press.

Groenewald, F. 2007. Socio-economic transformation in the South African banking sector - the case for "outside in" action learning. http://www.globalforum-actionlearning.com/index.php?option= com content\&view $=$ article $\&$ id $=54$ : sessions-2006\&catid $=28$ : previousforums $\&$ Itemid $=66$ (Accessed 8 November 2015).

Hopwood, N., D. Rooney, D. Boud and M. Kelly. 2016. Simulation in higher education: A sociomaterial view. Educational Philosophy and Theory 48(2): 165-178.

Jarbandhan, D. B. 2011. The evolution of leadership competencies for the South African public sector. Administratio Publica 19(2): 21-47.

Jewitt, C., G. Moss and A. Cardini. 2007. Pace, interactivity and multimodality in teachers' design of texts for interactive whiteboards in the secondary school classroom. Learning, Media and Technology 32(3): 303-317.

Jivan, A. M. 2017. Towards an integrative framework of leadership development in the South African banking industry. PhD dissertation, University of Witwatersrand.

Kanwar, A., S. K. Balasubramanian and A. Umar. 2013. Lifelong learning in South Africa. International Journal of Continuing Education and Lifelong Learning 5(2): 17.

Khurana, R. 2010. From higher aims to hired hands: The social transformation of American business schools and the unfulfilled promise of management as a profession. Princeton: Princeton University Press.

Kostogriz, A. 2006. Putting "space" on the agenda of sociocultural research. Mind, Culture, and Activity 13(3): 176-190.

Kostogriz, A. and E. Peeler. 2007. Professional identity and pedagogical space: Negotiating difference in teacher workplaces. Teaching Education 18(2): 107-122.

Koyama, J. P. and H. Varenne. 2012. Assembling and dissembling: Policy as productive play. Educational Researcher 41(5): 157-162.

Le Grange, L. 2000. A case study of changing pedagogical practices at a higher education institution. South African Journal of Higher Education 14(1): 152-159.

Mabey, C. and K. Morrell. 2011. Leadership in crisis: "Events, my dear boy, events". Leadership 7(2): $105-117$.

Mbembe, A. J. 2016. Decolonizing the university: New directions. Arts and Humanities in Higher Education 15(1): 29-45.

McGrath, S. and A. Badroodien. 2006. International influences on the evolution of skills development in South Africa. International Journal of Educational Development 26(5): 483-494.

Merriam, S. B. 2001a. Andragogy and self-directed learning: Pillars of adult learning theory. New Directions for Adult and Continuing Education 2001(89): 3-14.

Merriam, S. B. 2001b. Qualitative research and case study applications in education. San Francisco: Jossey-Bass Publishers.

Moisio, S. and A. Kangas. 2016. Reterritorializing the global knowledge economy: An analysis of geopolitical assemblages of higher education. Global Networks 16(3): 268-287.

Mulcahy, D., B. Cleveland and H. Aberton. 2015. Learning spaces and pedagogic change: Envisioned, enacted and experienced. Pedagogy, Culture \& Society 23(4): 575-595.

Parker, D. 2006. Official pedagogic identities from South African policy - some implications for mathematics teacher education practice. Pythagoras 63: 2-13.

Pendlebury, S. 1998. Transforming teacher education in South Africa: A space-time perspective. Cambridge Journal of Education 28(3): 333-349.

Richer, Z. 2015. Toward a social topography: Status as a spatial practice. Sociological Theory 33(4): $347-368$. 
South African Qualifications Authority. 2008. The National Qualifications Framework Act, Number 67. Pretoria: South African Qualifications Authority.

Stevenson, R. B. 2008. A critical pedagogy of place and the critical place(s) of pedagogy. Environmental Education Research 14(3): 353-360.

Taylor, C. A. 2013. Objects, bodies and space: Gender and embodied practices of mattering in the classroom. Gender and Education 25(6): 688-703.

Tuschling, A. and C. Engemann. 2006. From education to lifelong learning: The emerging regime of learning in the European Union. Educational philosophy and theory 38(4): 451-469.

Waghid, Y. 2008. The public role of the university reconsidered. Perspectives in Education 26(1): 1924.

Willis, J. 2014. Making space to learn: Leading collaborative classroom design. Journal of Educational Leadership, Policy and Practice 29(1): 3-16.

Yin, R. 2003. Case study research. Design and methods. London: Sage Publications. 